\title{
The Size and Strength Development in Elite Youth Ice Hockey Players
}

\author{
Jeff R. Leiter (Corresponding author) \\ Pan Am Clinic Foundation, 75 Poseidon Bay, Winnipeg R3M 3E4, Canada \\ E-mail: jleiter@panamclinic.com \\ Dean M. Cordingley \\ Pan Am Clinic Foundation, 75 Poseidon Bay, Winnipeg R3M 3E4, Canada \\ E-mail: dcordingley@panamclinic.com \\ Adam J. Zeglen \\ Focus Fitness, 3969 Portage Ave, Winnipeg R3K 1W4, Canada \\ E-mail: azeglen@truenorth.mb.ca \\ Glenn D. Carnegie \\ Focus Fitness, 3969 Portage Ave, Winnipeg R3K 1W4, Canada \\ E-mail: glenn.carnegie@ canucks.com \\ Peter B. MacDonald \\ Pan Am Clinic, 75 Poseidon Bay, Winnipeg R3M 3E4, Canada \\ E-mail: pmacdonald@panamclinic.com
}

Received: 09-06- 2016

doi:10.7575/aiac.ijkss.v.4n.3p.54
Accepted: 23-07- 2016

Published: 31-07- 2016

\begin{abstract}
Background: Ice hockey is a fast, physical sport that requires high levels of muscular strength, muscular endurance and agility. Objectives: This study was conducted to create a profile including: anthropometric measurement, muscular strength, muscular endurance, lower body jump height and distance, and agility characteristics for elite youth hockey players. Methods: Pre-season off-ice testing results were retrospectively reviewed from a human performance database. Variables included height, weight, body fat percentage, grip strength, push-ups/bench press, supine rows, the plank test, vertical jump, standing long jump, hip adductor and abductor strength, and the 5-10-5 shuttle, and. One-way ANOVAs (1group x 4 time) and Tukeys post-hoc tests were performed to determine changes in the immediately successive age group ( $\mathrm{p}<0.05)$. Results: Participants included male Bantam-(age: 13-14) and Midget-(age: 15-17) AAA ice-hockey players $(n=260)$. Age categories were grouped as 13 years old $($ yo $)(n=75), 14$ yo $(n=70), 15$ yo $(n=58)$, and 16-17 yo $(n=57)$. Increases between successive age groups were observed in the following variables: weight $(13,14,15$ and 16-17 yo), height (13 and 14 yo), left and right grip strength (13, 14, 15, and 16-17 yo), bench press (15 and 16-17 yo), left and right hip abduction (14, 15, and 16-17 yo), and vertical and standing long jump (13, 14, and 15 yo). Total time for the 5-10-5 shuttle run test decreased from 13 to 14 yo, and 14 to 15 yo. Conclusion: Changes with age in office performance variables of elite amateur hockey players should be recognized, followed, and addressed during player development to maximize the potential for elite performance and reduce the risk of injury.
\end{abstract}

Keywords: Athletic Performance, Training, Physical Fitness

\section{Introduction}

\subsection{Introduce the problem}

Ice hockey involves aggressive play at fast speeds, requiring near maximal heart rates (Jackson, Snydmiller, Game, Gervais, \& Bell, 2016), with a high frequency and magnitude of physical contact (Cox, Miles, Verde \& Rhodes, 1995; Montgomery, 2006). The majority of injuries in ice hockey are a result of a collision between two players (Azuelos, Pearsall, Turcotte \& Montgomery, 2004) and can be related to the discrepancy in size, strength and speed of the competitors (Montgomery, 2006), especially at the amateur level (Emery et al., 2011). During youth development, there can be a wide range of size, strength and skill levels amongst peers, and this variance may increase the risk of injury in youth hockey. At the time of data collection, Hockey Canada allowed body-checking beginning at the age of 12 (Peewee level). Hockey Canada since revised the rule for the start of the 2013-2014 season such that body-checking is not allowed until the age of 13 (Bantam level) (Hockey Canada, 2014). Physical development with respect to size and 
strength is important for these players to resist injuries (Gledhill \& Jamnik, 2007) and maximize performance, especially when transitioning to an older age group with players that may be larger, stronger and faster.

\subsection{Review of literature}

Prior to the NHL entry draft an athletic profile of each player is obtained through a combined series of standardized tests (referred to as a 'Combine') that evaluate the player's physical stature and physiological fitness level (Gledhill \& Jamnik, 2007). These tests include anthropometric measures (height, weight, body composition) and assessments of anaerobic and aerobic fitness, muscular power, muscular strength, muscular endurance and flexibility (Gledhill \& Jamnik, 2007). These tests were adopted and adapted for youth hockey players included in our study to establish size and strength profiles for each age group. National Hockey League (NHL) players have become heavier, taller and stronger (Montgomery, 2006) allowing them to optimize power for skating and shooting and maintain aggressive play while being less prone to injuries (Gledhill \& Jamnik, 2007). The size and athletic profile of NHL players are well documented and understood; there is a paucity of literature in youth hockey players. While age, division of play, body checking (Emery \& Meeuwisse, 2006), and position (Grant et al., 2015) can contribute to an increased risk of injury, the effects of body size and strength differences on injury rates in youth hockey have not been addressed. The purpose of this study was to investigate size and fitness differences amongst elite youth hockey players in successive age groups from 13-17 years. To our knowledge, this is the most comprehensive assessment of size and fitness differences by age category in elite youth hockey.

\section{Methods}

\subsection{Participants}

Participants included Bantam- (age: 13-14) and Midget- (age: 15-17) AAA hockey players (n=260) from 14 teams preparing to compete in the 2012-2013 season. All staff members were trained in the proper methodology for each test. At a pre-season meeting parents/guardians were informed that de-identified data could be used for research purposes and inclusion of this data was voluntary and were given the opportunity to exclude the data of their dependant(s). Ethical approval was received from the local research ethics board and the local hockey organization. All parents/guardians were informed that de-identified data from league testing could be used for research purposes. All parents/guardians were notified that inclusion of data was voluntary and could exclude the data of their dependant(s).

\subsection{Experimental Design}

This is a retrospective study in which our human performance database was reviewed for all AAA (13-17 year old hockey players who participated in a pre-season testing combine prior to the 2012-2013 season. Personal identifiers were removed for each athlete.

\subsection{Procedures}

Body mass was measured to the nearest $0.1 \mathrm{~kg}$ in shorts only using a calibrated electronic scale (Taylor, HoMedics Group Canada, Toronto, Ontario). Height was measured to the nearest $0.1 \mathrm{~cm}$ (Seca 700, Seca Precision for Health, Hamburg, Germany). Body fat was determined using skin folds at 7 sites (chest, triceps, subscapular, suprailiac, abdomen, front thigh and midaxillary) using skin-fold calipers (Chattanooga Baseline Skinfold Caliper, Chattanooga Group, Vista, CA) and body fat \% was calculated (Siri, 1961). This method has had R values reported between 0.888 and 0.918 (Jackson \& Pollock, 1978). All skinfolds were performed by the same experienced tester to ensure consistency between athletes.

Grip strength was used to assess upper body strength. Players were instructed to stand erect with elbows extended and arms to the side and squeeze the hydraulic grip dynamometer (Jamar hand dynamometer, Sammons Preston Rolyan, Bolingbrook, Il) with as much force as possible (Canadian Society for Exercise Physiology, 2003). Players performed three repetitions for each arm, alternating between arms after each repetition. The maximum force of each hand was recorded. Upper body muscular endurance was assessed with push-ups for Bantam players (age 13-14) and bench press for Midget players (age 15-17). The Bantam players were instructed to lay prone on the floor with hands positioned under each shoulder. For the 'push-up' phase, players were instructed to extend at the elbow into a push-up position. For the 'downward' phase, players were instructed to touch their chest against a $4 \mathrm{~cm}$ tall piece of foam. The test was stopped when players reached complete fatigue and/or could no longer maintain form during the upward or downward phase of the push-up. The Midget players performed a bench press with a resistance of $52.3 \mathrm{kgs}$ (115 lbs) to assess upper body strength. Each player was instructed to perform as many repetitions as possible to a maximum of 25 . During the 'downward' phase of all repetitions, the players were required to touch the bar to their chest. During the 'push' phase the players were instructed to reach full extension at the elbow joint. Feet were required to remain on the floor and the lower back/buttocks of the athlete were required to stay in contact with the bench.

Lower body strength was determined with hip abduction and adduction strength. Players were tested lying supine on an athletic therapy table. A hand-held dynamometer (DFX 2 Series Digital Force Gauge, Largo, FL) was placed $5 \mathrm{~cm}$ proximal to the medial (Adduction test) or lateral (Abduction test) malleoli of the ankle (Figure 1). A series of three, two second maximal isometric contractions were performed for the abductors and then adductors of each leg with 30 seconds of recovery between each contraction. Players alternated between legs after each repetition. The maximum value of each test was recorded to the nearest $0.1 \mathrm{~kg}$ of force. 


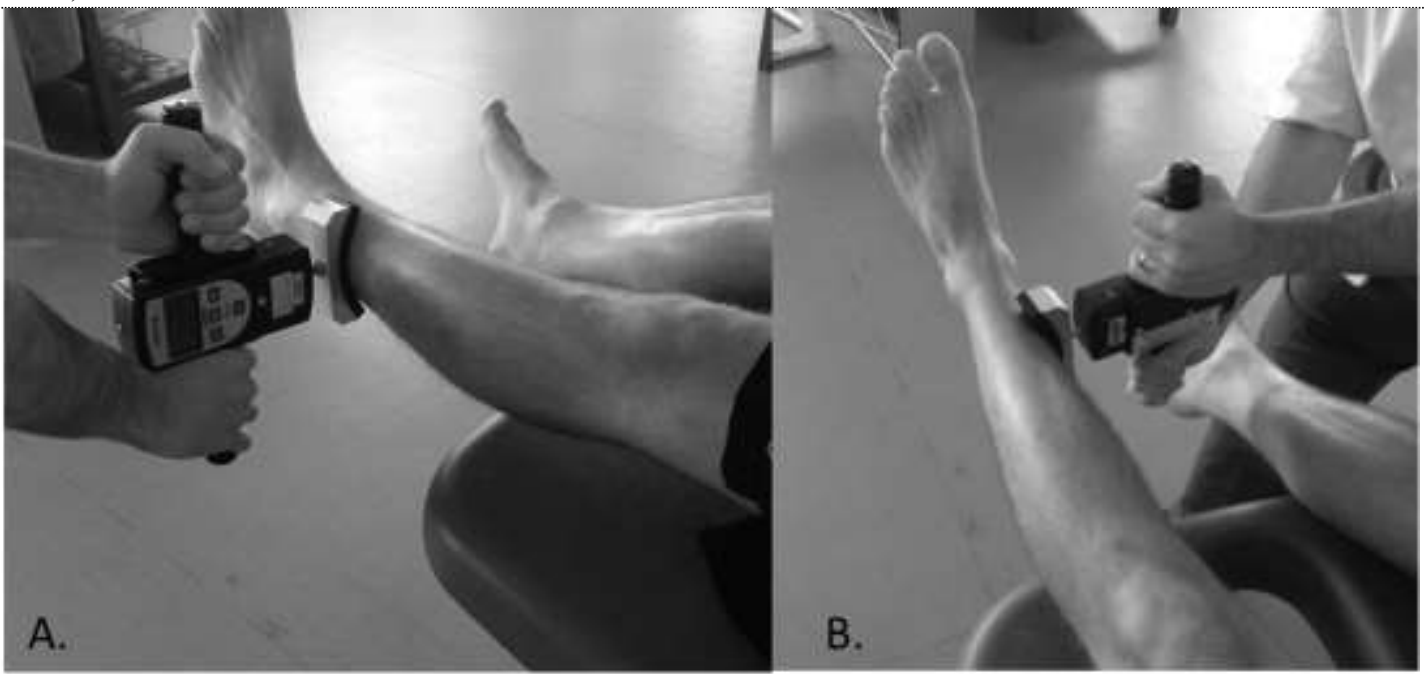

Figure 1. A. Force gauge placement for hip abduction strength testing. B. Force gauge placement for hip adduction strength testing

Upper back endurance was determined with supine rows. A barbell was placed on a squat rack $(34.5 \mathrm{~cm}$ from the ground), and the player positioned themselves under the bar with hands shoulder width apart and a pronated grip on the bar. Feet were placed shoulder width apart on the floor with knees flexed to 90 degrees and hips and trunk in a neutral position. When instructed, the player pulled until the chest of the athlete contacted the bar and then returned to the starting position with shoulders flexed and elbows extended. When a player could no longer touch the bar with their chest, the test was stopped and the number of repetitions recorded. Abdominal muscle and core endurance was assessed using a front plank. The athletes were instructed to have elbows and forearms on the ground with upper arms perpendicular to the ground. The athlete had to maintain a neutral spine and hold the position for as long as possible (up to 120 seconds). The length of time was recorded until the form of the athlete waivered or maximal fatigue was reached. Lower body vertical jump height and standing long jump distance was assessed. Vertical jump was measured to the nearest 0.5 inch $(1.27 \mathrm{~cm}$ ) using a Vertec Jump Trainer (Sports Imports, Columbus, OH). A standing reach height was first established. The athletes reached with their dominant hand to displace the highest bar (vane) possible on the Vertec while keeping their feet together and flat on the floor. Players then stood directly beneath the Vertec and performed a counter movement vertical jump attempting to touch the highest vane possible. Each player performed 3 repetitions and the highest height was recorded.

Standing long jump was measured to the nearest $0.5 \mathrm{~cm}$ using a cloth tape measure attached to the floor. The athletes stood with toes behind the start of the tape measure and were instructed to jump as far as possible. The distance traveled was measured to the heel that landed closest to the start line. Players performed three jumps and the longest distance was recorded. Multi-directional agility and speed were assessed with a 5-10-5 shuttle test. Three cones were placed along a straight line, five yards (4.57 meters) apart. Players started with their feet straddling the center cone and sprinted to the cone on his right or left side. The player touched the cone, then sprinted in the opposite direction to touch the far cone and finally reversed direction and sprinted to the centre cone. In total, the player covered 20 yards (18.3 meters). The test was performed four times, two times with the player going to the right first and two times with the player going to the left first. The fastest time for each direction was used in analysis.

\subsubsection{Data and Statistical analysis}

A one-way (1 group x 4 time) ANOVA was performed to determine an overall test of significance for the mean differences of all age groups. If a significant main effect was found, a Tukeys HSD (honestly significant difference) test was performed to identify which differences were significant. The alpha level was set at $\mathrm{p}<0.05$ to signify a significant difference for all analyses. SPSS 20.0 (IBM Corporation, Armonk, NY) was used to perform statistical analyses.

\section{Results}

\subsection{Anthropometric measures}

The number of athletes in each age category was Bantams: 13 yo $(n=75), 14$ yo $(n=70)$, and Midgets: 15 yo $(n=58), 16-$ 17 yo $(\mathrm{n}=57)$. All athletes were male. Anthropometric means are summarized (height, Figure 2; weight, Figure 3; body fat $\%$ and BMI, Table 1). Percentile data for height, weight and body fat percentage are presented (Table 2). The weight of athletes significantly increased with every successive age group, 13 to 14 ( $\mathrm{p}<0.001), 14$ to 15 ( $\mathrm{p}=0.005), 15$ to $16(\mathrm{p}=0.013)$ (Figure 3). The only increase in height was found between the 13 and 14 yo $(\mathrm{p}<0.001)$. There was no associated change in body fat with these physical changes, however BMI increased from ages 13 to 14 ( $p=0.024)$ and 14 to 15 ( $\mathrm{p}=0.012)$, but not 15 to $16(\mathrm{p}=0.204$; Table 1$)$. 
Table 1. Anthropometric and athletic profile measures according to age

\begin{tabular}{|c|c|c|c|c|}
\hline Age (yrs) & 13 & 14 & 15 & $16-17$ \\
\hline $\mathrm{n}=$ & $75 t$ & $70 \#$ & $58 \&$ & $57 \dagger$ \\
\hline Body Fat (\%) & $9.3(3.5)$ & $9.3(3.5)$ & $9.8(3.7)$ & $11.0(3.5)$ \\
\hline Body Mass Index (kg/m2) & $20.6(2.1)$ & $21.7(1.9)^{*}$ & $22.9(2.5)^{*}$ & $23.7(2.2)$ \\
\hline Push-ups (reps) & $25.0(9.9)$ & $25.0(12.8)$ & $\mathrm{n} / \mathrm{a}$ & $\mathrm{n} / \mathrm{a}$ \\
\hline Bench-press (reps) & $\mathrm{n} / \mathrm{a}$ & $\mathrm{n} / \mathrm{a}$ & $9.78(5.8)$ & $17.0(7.8)^{*}$ \\
\hline Supine row (reps) & $18.5(7.2)$ & $19.9(8.0)$ & $22.0(6.7)$ & $23.1(8.1)$ \\
\hline Plank (s) & $112.6(16.8)$ & $114.6(15.3)$ & $116.2(13.0)$ & $118.2(8.5)$ \\
\hline Vertical jump (cm) & $43.9(7.9)$ & $47.5(6.1)^{*}$ & $52.8(8.9) *$ & $53.3(10.16)$ \\
\hline 5-10-5 shuttle (s) & $5.5(0.3)$ & $5.3(0.2)^{*}$ & $5.2(0.2)^{*}$ & $5.1(0.2)$ \\
\hline Adduction left leg (kg) & $14.6(3.3)$ & $15.8(3.2)$ & $16.6(3.3)$ & $19.2(3.4)^{*}$ \\
\hline Adduction right leg (kg) & $14.6(3.3)$ & $16.1(3.5)$ & $17.5(3.7)$ & $19.0(3.2)$ \\
\hline Abduction left leg (kg) & $14.6(2.9)$ & $15.3(2.4)$ & $16.9(3.2)^{*}$ & $19.0(3.3)^{*}$ \\
\hline Abduction right leg (kg) & $14.8(3.1)$ & $15.5(2.7)$ & $17.0(3.7)^{*}$ & $19.5(2.9)^{*}$ \\
\hline Left/Right leg Adduction & $1.00(0.11)$ & $0.99(0.12)$ & $0.96(0.13)$ & $1.0(0.11)$ \\
\hline Left/Right leg Abduction & $0.99(0.09)$ & $1.00(0.12)$ & $1.01(0.12)$ & $0.98(0.09)$ \\
\hline Ad/Abduction left leg & $1.01(0.16)$ & $1.03(0.16)$ & $1.00(0.16)$ & $1.02(0.16)$ \\
\hline Ad/Abduction right leg & $0.99(0.17)$ & $1.05(0.17)$ & $1.05(0.18)$ & $0.98(0.11)$ \\
\hline
\end{tabular}

Data represented as means (SD). Each age category was compared to the immediately successive age group. $*$ indicates a significant difference, $\mathrm{p}<0.05$.

$\$$ For supine rows one athlete did not complete this test due to injury

\# For push-ups, supine rows and 5-10-5 shuttle run, two athletes did not complete each test and one athlete did not complete vertical jump.

\& For vertical jump, plank, and left hip adduction and abduction, one athlete did not complete the tests while two athletes did not complete the 5-10-5 shuttle, five did not complete supine rows and 7 did not complete bench press due to injuries.

${ }^{\dagger}$ For bench press, standing long jump, vertical jump and 5-10-5 shuttle run, one athlete did not complete these tests while two athletes did not complete the supine rows due to injury.

Table 2. Percentiles for anthropometric measures

\begin{tabular}{|c|c|c|c|c|c|c|c|c|}
\hline & & \multicolumn{7}{|c|}{ Percentile } \\
\hline & Age (yrs) & 5 & 10 & 25 & 50 & 75 & 90 & 95 \\
\hline \multirow{4}{*}{ 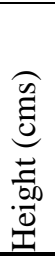 } & 13 & 154.0 & 160.0 & 162.6 & 165.1 & 172.7 & 180.0 & 180.8 \\
\hline & 14 & 165.0 & 167.6 & 170.1 & 175.0 & 179.0 & 182.9 & 185.4 \\
\hline & 15 & 166.0 & 167.6 & 172.7 & 177.8 & 182.9 & 185.4 & 186.1 \\
\hline & $16-17$ & 167.8 & 172.5 & 175.3 & 180.3 & 185.4 & 189.7 & 193.0 \\
\hline \multirow{4}{*}{ 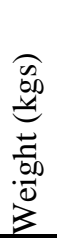 } & 13 & 45.9 & 47.5 & 51.9 & 56.3 & 62.1 & 69.8 & 77.1 \\
\hline & 14 & 55.4 & 57.0 & 61.6 & 65.5 & 71.4 & 76.3 & 83.0 \\
\hline & 15 & 59.4 & 61.0 & 64.6 & 68.5 & 79.6 & 85.7 & 94.7 \\
\hline & $16-17$ & 62.9 & 66.6 & 72.1 & 75.8 & 81.1 & 89.4 & 96.8 \\
\hline \multirow{4}{*}{ 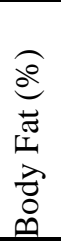 } & 13 & 16.5 & 15.2 & 11.2 & 8.3 & 6.9 & 5.4 & 4.7 \\
\hline & 14 & 16.9 & 14.4 & 11.7 & 8.2 & 7.0 & 5.8 & 5.5 \\
\hline & 15 & 19.4 & 15.6 & 11.8 & 9.1 & 7.1 & 6.0 & 5.3 \\
\hline & $16-17$ & 18.0 & 15.9 & 13.3 & 10.7 & 8.3 & 6.8 & 6.2 \\
\hline
\end{tabular}




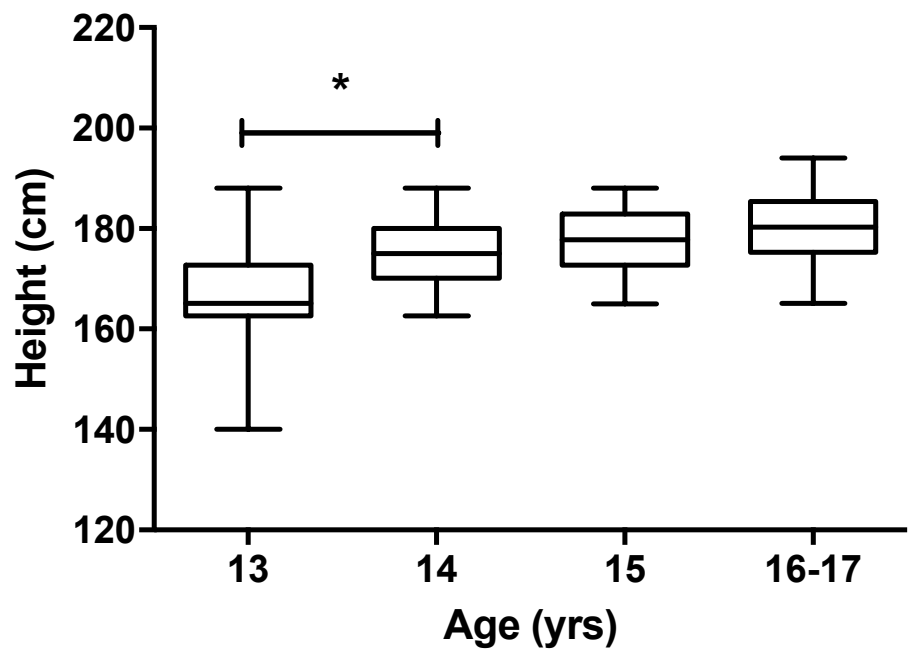

Figure 2. Changes in height $(\mathrm{cm})$ between age groups of elite youth hockey players. * indicates a significant difference, $\mathrm{p}<0.05$.

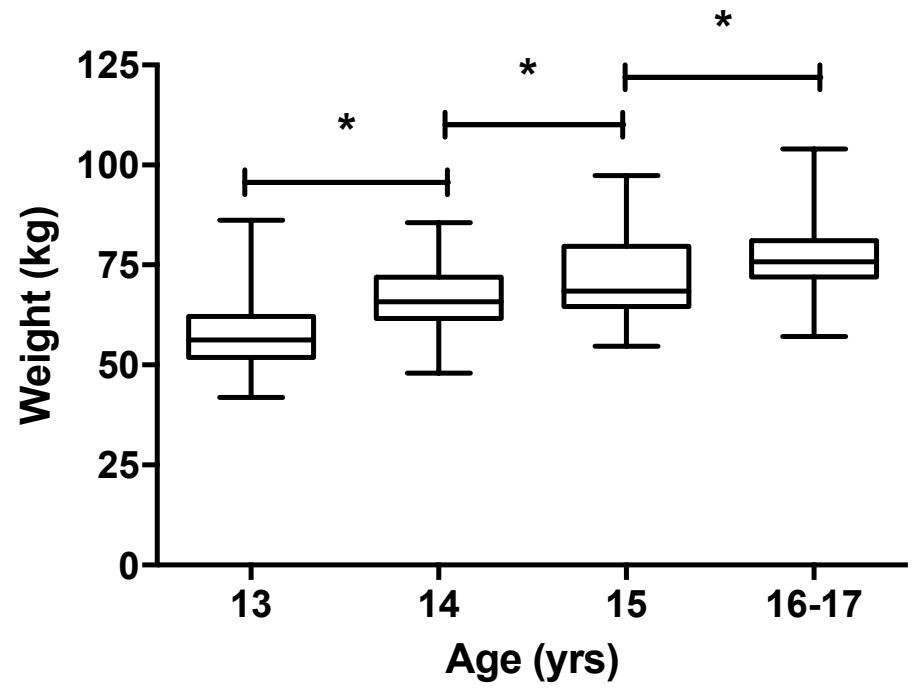

Figure 3. Changes in body weight $(\mathrm{kg})$ between age groups of elite youth hockey players. * indicates a significant difference, $\mathrm{p}<0.05$.

\subsection{Fitness measures}

Grip strength increased significantly with all successive age groups for both the left- and right-hand (Figure 4). There was no difference between the 13 and 14 yo athletes who performed push-ups to fatigue $(\mathrm{p}=0.98)$, but there was a difference between the 15 and 16 yo athletes (Midget players) for bench press repetitions to fatigue $(\mathrm{p}<0.001$; Table 1$)$. Since Bantam (push-up) and Midget (115 lbs bench press) players were instructed to use different resistance exercises a statistical comparison between the 14 and 15 yo was not performed.

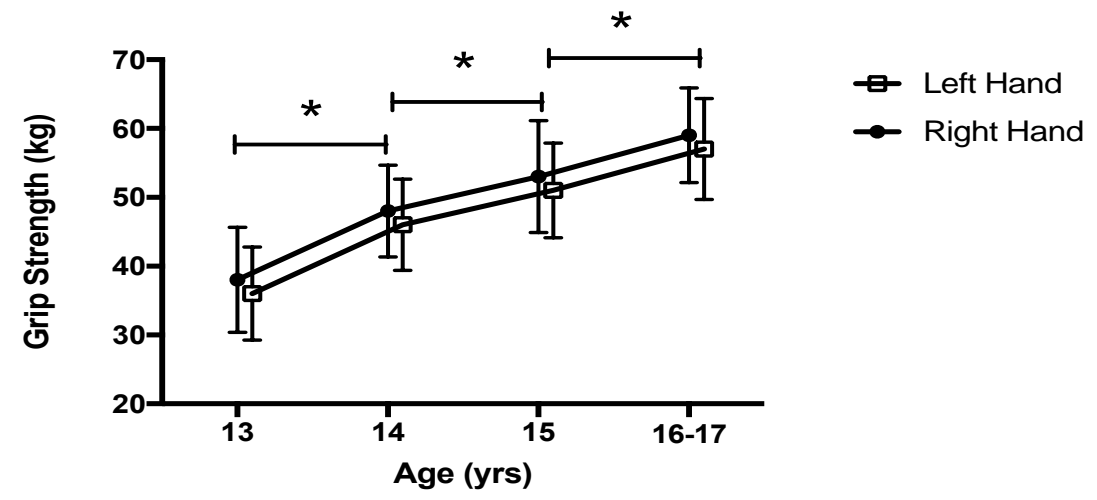

Figure 4. Changes in left and right hand grip strength $(\mathrm{kg})$ between age groups of elite youth hockey players. * indicates a significant difference, $\mathrm{p}<0.05$. 
With respect to lower body strength, hip abduction strength increased in both the left and right legs between the 14 and 15 yo $(\mathrm{p}=0.019$ and $\mathrm{p}=0.032$, respectively) and 15 to 16 yo $(\mathrm{p}=0.001$ and $\mathrm{p}=<0.001$, respectively). The only increase in hip adduction strength was observed in the left legs of the 15 to 16 year-olds $(\mathrm{p}<0.001)$. The ratio of adductor to abductor strength of the right and left legs of all age groups demonstrated that adductor strength was at least $98 \%$ of abductor strength. However, 21 players $(9 \%)$ had an adductor to abductor strength ratio less than 0.80 in at least one leg, and seven (3\%) in both legs suggesting an adductor muscle imbalance. All hip ab/adduction ratios are summarized in Table 1.

\subsection{Jump height and distance}

The distance a player was able to achieve performing the standing long jump test increased from the ages of 13 to 14 $(\mathrm{p}<0.001)$ and 14 to 15 years $(\mathrm{p}<0.001)$, but not from 15 to 16 years $(\mathrm{p}=0.867$;Figure 5). Similarly, vertical jump scores increased in the younger age groups, but not the 15 to 16 yo groups $(\mathrm{p}=0.99)$.

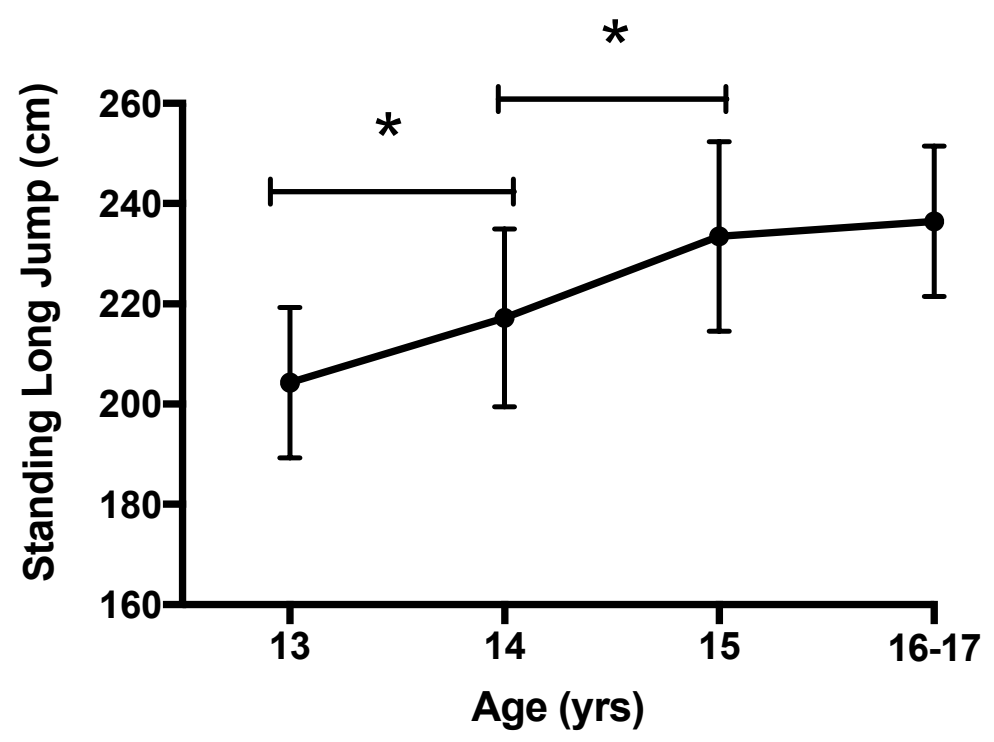

Figure 5. Changes in standing long jump distance $(\mathrm{cm})$ between age groups of elite youth hockey players. * indicates a significant difference, $\mathrm{p}<0.05$.

\subsection{Agility measures}

Time to complete the 5-10-5 shuttle run decreased as the athletes increased in age from 13 to 14 (p<0.001) and 14 to 15 $(\mathrm{p}=0.006)$. Although performance times continued to improve between the 15 and 16 yo athletes significance was not reached $(\mathrm{p}=1.0)$.

\subsection{Muscular endurance}

There were no changes observed in upper back, abdominal or core endurance results between successive age groups (Table 1).

\section{Discussion}

The most important finding of this study was that the greatest changes in size and strength occur between the ages of 13- and 15- years of age. Since this is a period of development where body-checking is introduced and skill levels may demonstrate the greatest variability, size and strength may factor in to injury risk more so than at the later ages. To our knowledge, this is the most comprehensive assessment of size and strength of elite youth hockey players to date.

The height of players increased in succeeding age groups from 13 to 14 years of age which corresponds to the onset of puberty for males (Rogol, Roemmich \& Clark, 2002). In 1984-1985, Regnier et al.(1989) reported that the average height of 13-14 year old players $(n=58)$ was $164.5(6.14)$ compared to $167.6(8.4)$ in our study. There was an increase in body mass between all age groups in our study. Bantam and Midget athletes in our study demonstrated ranges in mass of $96.14 \mathrm{lb}(43.7 \mathrm{kgs})$ and $108.46 \mathrm{lb}$ (49.3) respectively. Emery and Meeuwisse (2006) reported body mass ranges for Pee Wee, Bantam and Midget as high as $130 \mathrm{lb}, 130 \mathrm{lb}$ and $115 \mathrm{lb}$ respectively (Emery \& Meeuwisse, 2006). This large discrepancy in the mass of players within the same age group has been theorized to contribute to increased injury risk. At the University level of competition, Grant and colleagues (2015) demonstrated that for each $5 \mathrm{~kg}$ increase in body mass, injury rate increased by a factor of 1.3 and for players with a BMI $>25 \mathrm{~kg} / \mathrm{m}^{2}$, the risk of injury was 2.1 times higher than players with a BMI $<25 \mathrm{~kg} / \mathrm{m}^{2}$. Of our athletes, 9\% $(\mathrm{n}=23)$ presented with a BMI $>25 \mathrm{~kg} / \mathrm{m}^{2}$ potentially putting them at a higher risk of injury. Conversely, smaller players (i.e. $<37 \mathrm{~kg}$ ) have been shown to be at a greater risk of injury in Pee Wee(Emery et al., 2010), but there is no association between body mass and injury risk at the Bantam level( Emery et al., 2011). A limitation in the youth hockey studies is that strength and body fat percentage were not measured, which is a potential reason for the discrepancy between studies.

The increase in body mass in each age group did not result in a change in body composition with the average body fat recorded at $9.8 \%$ for all players. Since body fat percentage remained consistent despite an increase in mass; this 
ensured an optimal strength/mass ratio. In theory, an optimal strength/mass ratio would allow players to move their own body weight as fast and efficiently as possible. Although body fat percentage is an indicator of optimal strength/mass ratio, it has not been shown to be a predictor of injury risk(Grant et al., 2015). Over time, the athlete has changed with the ultimate goal of optimizing size and strength. Quinney et al.(2008) longitudinally tracked NHL athletes over a 26 year period (1979 to 2005) and found an increase in body mass without a concurrent change in body composition, indicating body mass gains are due to lean body mass and not fat mass. Montgomery (2006) noted that NHL players with the Montreal Canadiens hockey team in the year 2003 were on average $17 \mathrm{~kg}$ heavier and $10 \mathrm{~cm}$ taller than players in 1917, which he attributed to changes in nutrition, strength and conditioning and the recruiting processes. Increases in body mass have also been observed in the National Football League (1972-1998)(Snow, Millard-Stafford \& Rosskopf, 1998; Wilmore \& Haskell, 1972) and the general Canadian population (1981-1996)(Tremblay, Katzmarzyk \& Willms, 2002). It appears that the trend for heavier and taller athletes with optimal strength/mass ratios could be due to changes in training habits, nutrition as well as micro-evolution of the entire population.

When compared to normative data for the same aged youth(Mathiowetz, Wiemer, \& Federman, 1986) grip strength was considerably higher in our study suggesting that elite youth hockey players incur greater demands on upper body strength than the average adolescent. Unpublished data from our lab demonstrates that the average grip strength of NHL players is $67.8 \mathrm{~kg}$ and $68.8 \mathrm{~kg}$ for the left and right hands, respectively. Although the average grip strength of NHL players is greater than all groups tested in our study, this is an attainable value based on the chronological trends of our sample. In addition to sport, grip strength is a useful measure to predict mortality later in life. Males with higher grip strength in the middle years of life have a lower long-term mortality risk, even when education, occupation, age, physical activity, smoking, and body height are taken into account(Rantanen et al., 2000). There was no change in mean number of push-ups between 13 and 14 year olds, however there was a significant difference between 15 and 16 year olds (bench press). Interestingly, Grant and colleagues (2015) demonstrated that for every increase in 5 reps of barbell bench press $(84.1 \mathrm{~kg})$, injury risk increased by 1.3 times in University players. It is likely that stronger players play a more physical style and engage in body contact more often, which would increase the risk of injury. Although a statistical comparison was not employed between the 14 and 15 year olds due to the difference in tests (push-up vs. bench press), estimated comparisons were performed unsatisfactorily. During the push-up down phase (elbows flexed and shoulders extended), players supported approximately $75 \%$ of body weight and $69 \%$ during the upward phase (elbows extended and shoulders flexed)(Suprak, Dawes, \& Stephenson, 2011). Therefore, it can be estimated that the 13 and 14 year old players moved a maximum resistance of 43.5 and $50.2 \mathrm{~kg}$, respectively, based on average body weight for each group. This is similar to the $52.3 \mathrm{~kg}(115 \mathrm{lbs})$ of resistance used for the bench press test in the 15 and 16 year old age groups. However, since the 14 year olds performed a mean of 25 push-ups, indicating they are in the $95^{\text {th }}$ percentile for their age group(Catley \& Tomkinson, 2011) while the 15 year olds performed an average of only 9.78 bench press reps, statistical comparison of muscle isolation exercises (i.e. bench press) with total body exercises (i.e. push ups) is not recommended. Hip adductor and abductor strength are is paramount for the sport of ice hockey. Activation of the adductor and abductor muscle groups is required to perform a skating motion, (de Koning, de Groot, \& van Ingen Schenau, 1991) and is positively correlated with skating speed(Chang, Turcotte, \& Pearsall, 2009). Muscle imbalances in hip ad/abductor strength may predispose a hockey player to muscle strains of the adductor musculature. Tyler and colleagues (2001) reported that a hockey player is 17 times more likely to sustain an adductor strain if adductor strength is less than $80 \%$ of the abductor strength of the ipsilateral leg. Our research identified $9 \%$ of players with a ratio less than $80 \%$ in at least one leg and 3\% in both legs. Specific training programs should be designed for these players to balance muscle strength and reduce the risk of adductor strains, due to the debilitating nature of this injury and the risk or re-injury (2.6 times greater in players that have had an adductor injury)(Emery, Meeuwisse \& Powell, 1999).

Both standing long jump and vertical jump increased between the 13 and 14 year olds and the 14 and 15 year olds. The results observed with our athletes (vertical jump, $49.3 \pm 8.6 \mathrm{~cm}$; standing long jump, $221.4 \pm 21.3 \mathrm{~cm}$ ) are similar to those previously observed for 36 elite hockey players 15-22 years of age (vertical jump, $51.4 \pm 6.7 \mathrm{~cm}$; standing long jump, $210 \pm 19 \mathrm{~cm})($ Farlinger, Kruisselbrink, \& Fowles, 2007). Players also showed an improvement in 5-10-5 agility shuttle run performance each year up to and including 15 years of age. The physical maturation and increased musculoskeletal fitness level of the athletes aged 13-15 are consistent with males experiencing the onset of puberty at age 13(Rogol et al., 2002). Although athletes at this age are going through many physical changes, it is agreed that physical training does not inhibit growth and development if appropriate nutrient intake is achieved(Rogol et al., 2002). With respect to injuries, this manuscript addresses a limitation in most epidemiological manuscripts investigating injuries in youth hockey players. Although this study did not address injury rates, our results do address not only size, but also fitness differences that have not been thoroughly investigated in youth hockey players.

\subsection{Practicle applications}

Athletic profiles of elite youth ice hockey players change between succeeding age groups. Strength training may help eliminate any large physiological jumps between age groups. Understanding how strength, power, endurance and agility develops in youth can not only assist the hockey community with creating appropriate training programs, but also provide public health organizations with valuable information when developing activity guidelines for youth in general. 


\section{Conclusion}

This study demonstrated that there are many strength and size changes that take place between immediately succeeding age groups, which could make it challenging for an athlete to transition to the next age group in elite sports. The normative data set has potential implications on training programs with the creation of bench marks at each age to help assess an athlete's anthropometric characteristics, musculoskeletal fitness and agility.

\section{Acknowledgments}

Financial assistance was provided by the Pan Am Clinic Foundation. The authors would also like to acknowledge Focus Fitness for their assistance with all testing and the use of their space, Treny Sasyniuk for support with the writing of this manuscript, and all participants and the AAA hockey organization for their support. The authors have no conflict of interest to report.

\section{References}

Azuelos, Y.H., Pearsall, D.J., Turcotte, R., \& Montgomery, D.L. (2004). A review of ice hockey injuries: location, diagnosis, mechanism. In Pearsall, D.J. \& Ashare, A.B. (Eds.), Safety in ice hockey (Vol. 4, pp. 59-67). West Conshohcken, Penn.: American Society for Testing and Materials International.

Canadian Society for Exercise Physiology. (2003). The Canadian physical activity, fitness and lifestyle approach: CSEP-Health \& Fitness Program's Health-Related Appraisal and Counselling Strategy. (3rd ed.). Ottawa, ON.

Catley, M. J., \& Tomkinson, G. R. (2011). Normative health-related fitness values for children: analysis of 85347 test results on 9-17-year-old Australians since 1985. British Journal of Sports Medicine, 47(2), 98-108.

Chang, R., Turcotte, R., \& Pearsall, D. (2009). Hip adductor muscle function in forward skating. Sports Biomechanics, 8(3), 212-222. http://doi.org/10.1080/14763140903229534

Cox, M. H., Miles, D. S., Verde, T. J., \& Rhodes, E. C. (1995). Applied physiology of ice hockey. Sports Medicine (Auckland, NZ), 19(3), 184.

de Koning, J. J., de Groot, G., \& van Ingen Schenau, G. J. (1991). Coordination of leg muscles during speed skating. Journal of Biomechanics, 24(2), 137-146.

Emery, C. A., Kang, J., Shrier, I., Goulet, C., Hagel, B. E., Benson, B. W., Meeuwisse, W. H. (2010). Risk of injury associated with body checking among youth ice hockey players. JAMA, 303(22), 2265-2272.

Emery, C. A., \& Meeuwisse, W. H. (2006). Injury Rates, Risk Factors, and Mechanisms of Injury in Minor Hockey. The American Journal of Sports Medicine, 34(12), 1960-1969. http://doi.org/10.1177/0363546506290061

Emery, Carolyn A., Meeuwisse, Willem H., \& Powell, John W. (1999). Groin and Abdominal Strain Injuries in the National Hockey League. Clinical Journal of Sport Medicine, 9(3), 151-156.

Emery, C., Kang, J., Shrier, I., Goulet, C., Hagel, B., Benson, B., Meeuwisse, W. (2011). Risk of injury associated with bodychecking experience among youth hockey players. Canadian Medical Association Journal, 183(11), 1249-1256.

Farlinger, C. M., Kruisselbrink, L. D., \& Fowles, J. R. (2007). Relationships to skating performance in competitive hockey players. Journal of Strength and Conditioning Research, 21(3), 915.

Gledhill, N., \& Jamnik, V. (2007). Detailed assessment protocols for NHL entry draft players. York University, Toronto.

Grant, J. A., Bedi, A., Kurz, J., Bancroft, R., Gagnier, J. J., \& Miller, B. S. (2015). Ability of preseason body composition and physical fitness to predict the risk of injury in male collegiate hockey players. Sports Health: A Multidisciplinary Approach, 7(1), 45-51.

Hockey Canada. (2014). Referee's Case Book/Rule Combination 2014-2015. Hockey Canada. Retrieved from http://cdn.agilitycms.com/hockey-canada/Hockey-Programs/Officiating/Downloads/rulebook_casebook_e.pdf

Jackson, A. S., \& Pollock, M. L. (1978). Generalized equations for predicting body density of men. British Journal of Nutrition, 40(03), 497-504.

Jackson, J., Snydmiller, G., Game, A., Gervais, P., \& Bell, G. (2016). Movement Characteristics and Heart Rate Profiles Displayed by Female University Ice Hockey Players. International Journal of Kinesiology and Sports Science, 4(1). http://doi.org/10.7575/aiac.ijkss.v.4n.1p.43

Mathiowetz, V., Wiemer, D. M., \& Federman, S. M. (1986). Grip and pinch strength: norms for 6-to 19-year-olds. The American Journal of Occupational Therapy, 40(10), 705-711.

Montgomery, D. L. (2006). Physiological profile of professional hockey players-a longitudinal comparison. Applied Physiology, Nutrition, and Metabolism, 31(3), 181-185.

Quinney, H. A., Dewart, R., Game, A., Snydmiller, G., Warburton, D., \& Bell, G. (2008). A 26 year physiological description of a National Hockey League team. Applied Physiology, Nutrition, and Metabolism, 33(4), 753-760. 
Rantanen, T., Harris, T., Leveille, S. G., Visser, M., Foley, D., Masaki, K., \& Guralnik, J. M. (2000). Muscle strength and body mass index as long-term predictors of mortality in initially healthy men. The Journals of Gerontology Series A: Biological Sciences and Medical Sciences, 55(3), M168-M173.

Regnier, G., Boileau, R., Marcotte, G., Desharnais, R., Larouche, R., Bernard, D., Boulanger, D. (1989). Effects of Body-Checking in the Pee-Wee (12 and 13 Years Old) Division in the Province of Quebec. In C. R. Castaldi \& E. F. Hoerner (Eds.), Safety in Ice Hockey (Vol. 1, pp. 84-94). Philadelphia, PA: ASTM International.

Rogol, A. D., Roemmich, J. N., \& Clark, P. A. (2002). Growth at puberty. Journal of Adolescent Health, 31(6), 192200.

Siri, W.E. (1961). Body composition from fluid space and density. In Techniques for measuring body composition (J. Brozek and A. Henschel, pp. 223-224). Washington D.C.: National Academy of Sciences.

Snow, Teresa K., Millard-Stafford, Mindy, \& Rosskopf, Linda B. (1998). Body Composition Profile of NFL Football Players. Journal of Strength and Conditioning Research, 12(3), 146-149.

Suprak, D. N., Dawes, J., \& Stephenson, M. D. (2011). The effect of position on the percentage of body mass supported during traditional and modified push-up variants. The Journal of Strength \& Conditioning Research, 25(2), 497-503.

Tremblay, M.S., Katzmarzyk, P.T., \& Willms, J.D. (2002). Temporal trends in overweight and obesity in Canada, 19811996. International Journal of Obesity, 26(4), 538-543.

Tyler, T. F., Nicholas, S. J., Campbell, R. J., \& McHugh, M. P. (2001). The association of hip strength and flexibility with the incidence of adductor muscle strains in professional ice hockey players. The American Journal of Sports Medicine, 29(2), 124-128.

Wilmore, J.H., \& Haskell, W.L. (1972). Body composition and endurance capacity of professional football players. Journal of Applied Physiology, 33(5), 564-567. 